\title{
UN ACERCAMIENTO A LA ESTÉTICA DEL ARTE RUPESTRE DEL VALLE DEL MEZQUITAL, MÉXICO'
} AN APPROACH TO THE ASTHETICS OF ROCK ART FROM MEZQUITAL VALLEY,
MEXICO

\author{
FÉlIX LERMA*, NiCTÉ HERNÁNDEZ* * \& \\ DANIELA PEÑA ***
}

Este trabajo trata sobre el arte rupestre del valle del Mezquital, estado de Hidalgo, México, asociado histórica y culturalmente al grupo indígena otomí. Partimos de un ejercicio de observación directa de las pinturas con el objetivo de indagar en las características propias de una estética regional, durante este proceso de estudio hemos destacado la coherencia y la unidad discursivas presentes en diversos conjuntos, así como la interacción entre forma rocosa y acción pictórica. Por otra parte, también señalamos el carácter ritual y religioso de estas manifestaciones, las cuales muestran una estrecha relación con procesos culturales vinculados al territorio y al devenir del pueblo creador a través del tiempo.

Palabras clave: arte rupestre, estética, valle del Mezquital, centro de México, otomíes

This work approaches the rock art of the Mezquital Valley, Hidalgo, Mexico, attributed cultural and historical to the Otomi indigenous group. We started from our direct observation of the paintings with the objective to investigate into the own features of an regional aesthetic, during this study process we have bighlighted the discursive coherence and unity in different pictorial sets, and also the interaction between the rock form and the pictorial action. Moreover, we also signalize the ritual and religious character of these manifestations, which show a close relationship with cultural processes linked to the territory and to the advent of the creative people through the time.

Key words: rock art, aesthetic, Mezquital Valley, Central Mexico, Otomi

\section{¿QUÉ HAY SOBRE LA ROCA?}

A partir de 2005 iniciamos nuestros recorridos en la región del valle del Mezquital, ubicada en el occidente del actual estado de Hidalgo, con el objeto de acercarnos a las pinturas rupestres que se encuentran diseminadas en las barrancas que abundan en este territorio semidesértico. De manera paulatina pudimos identificar algunas constantes en el grafismo rupestre y su entorno gracias a un ejercicio de observación que consistió en un proceso de "aprender a ver", el que nos llevó a preguntarnos no solo por la identificación de los motivos, sino también por la unidad discursiva de las distintas representaciones rupestres entre sí, su ubicación precisa en determinadas formaciones rocosas y las cualidades espaciales de los lugares de emplazamiento. Desde un inicio contábamos con registros y catálogos de los sitios y los motivos realizados por otros autores, los cuales fueron materiales de consulta fundamentales en este primer proceso de reconocimiento (Lorenzo 1992; Illera 1994; Ochatoma 1994). También nos percatamos de que existía un importante camino de exploración del arte rupestre en el análisis de distintos elementos que lo vinculan con la cultura Otomí de la región, entre ellos destaca la exégesis que se ha conservado en algunas comunidades sobre algunos de los conjuntos rupestres y la presencia de importantes paralelismos entre estas

* Félix Lerma, UNAM, Posgrado en Historia del Arte, email: teotecuani@gmail.com

* Nicté Hernández, UNAM, Colegio de Historia, Facultad de Filosofía y Letras, email: nictekate@hotmail.com

*** Daniela Peña, UNAM, Colegio de Historia, Facultad de Filosofía y Letras, email: daniacps@gmail.com 
manifestaciones y las prácticas religiosas de los otomíes actuales (Vite Hernández 2012). Durante este acercamiento a la tradición cultural otomí y al arte rupestre del valle del Mezquital fue fundamental la colaboración con el historiador otomí Francisco Luna, profundo conocedor de la cultura y la historia de la región. De esta manera se conformó un proceso de diálogo y retroalimentación entre el señor Luna y el equipo de trabajo, lo que se tradujo en un proceso colectivo de aprendizaje. ${ }^{2}$

Una de las claves más importantes que nos dio el acercamiento a la tradición otomí fue el reconocimiento de los sitios de arte rupestre como lugares en donde fueron plasmados temas de carácter ritual y religioso, tanto de índole prehispánica como colonial, que funcionaron como lugares de aprendizaje y de transmisión del conocimiento ancestral. Esto nos ha llevado a proponer que el arte rupestre constituyó un elemento fundamental en la conformación de un cristianismo otomí, el que se gestó en una época de profundos cambios socioculturales suscitados a partir del siglo xvi. Esta propuesta nos hizo indagar por la manera misma en que el arte rupestre funcionaba en términos de discurso expresivo que fungía como medio de transmisión de antiguas tradiciones y de inclusión de las innovaciones del mundo cristiano y colonial.

Pese a las diferencias y las discusiones que entraña el concepto de estética, con él se alude a la presencia de un universo de relaciones sensibles que todos los seres humanos establecemos con el mundo y sus objetos (Sánchez Vázquez 1992: 13; Heyd 2008: 1). El arte rupestre, entendido como las manifestaciones gráficas y espaciales hechas sobre superficies rocosas de entornos naturales o retocadas in situ, es expresado y aprehendido de manera sensible. Identificamos elementos como el color, la textura, la consistencia del trazo pictórico o la relación espacial que guardan distintos trazos y motivos entre sí (jerarquía, tamaño, composición, ritmo, repetición), los cuales son rasgos propios de las manifestaciones rupestres que implican su reconocimiento por medio de la percepción estética. Una aproximación a la estética del arte rupestre debe contemplar las obras no solo en tanto actividad gráfica, sino también como creaciones que integran un contexto más amplio: paisaje natural, formas rocosas, relación entre los conjuntos pictóricos y el entorno, entre otros. Este tipo de aspectos no se encontraba reflejado o debatido en la literatura existente sobre el arte rupestre del valle del Mezquital, por lo que consideramos que la indagación sobre estos aspectos resultaba pertinente.

Sin pretender la objetividad, el papel del investigador es captar la mayor cantidad de elementos que puedan coadyuvar a la comprensión de un determinado corpus de arte rupestre: tanto rasgos del grafismo como de su emplazamiento espacial en distintas escalas. En este sentido, la etapa de registro puede ser vista como un proceso en el cual el investigador extrae una serie de consideraciones que tienen su origen en la percepción de cualidades sensibles de distinto tipo. En el caso concreto de esta investigación, el proceso de registro en equipo permitió generar documentaciones y análisis más completos del arte rupestre, con el objetivo de descifrar las implicaciones estéticas y de otra índole por las que fueron creadas las obras. Este proceso también contempló la valoración de informaciones suministradas por otras fuentes o disciplinas, en particular, la historia, la arqueología y la etnografía (López Aguilar \& Fournier 1989; López Aguilar 1992; Fournier 2007).

El reto se presenta por igual a todos los que nos acercamos al arte rupestre: ¿cómo podemos traducir la percepción que tenemos de él hacia una comprensión más amplia de las implicaciones de estas manifestaciones en términos de su significado, su forma de enunciación o la identificación de sus elementos constitutivos?, ¿podemos acaso acercarnos a las características de una estética rupestre indígena a partir de la identificación de rasgos compositivos recurrentes y de los recursos expresivos empleados? Lo que se presenta en las siguientes páginas es una respuesta afirmativa a esta última pregunta.

\section{ARTE RUPESTRE EN EL PAISAJE DEL VALLE DEL MEZQUITAL}

\section{Contexto histórico-cultural}

El valle del Mezquital durante el Posclásico Tardío (siglos XIV al XVI) fungió como frontera cultural entre grupos mesoamericanos del centro del actual territorio mexicano y nómadas o seminómadas que habitaban en el norte (Kirchhoff 1943; Braniff 1994) (fig. 1). Si bien el centro de México es asociado la mayoría de las veces a los nahuas, es importante mencionar la presencia de otros grupos, entre ellos los pertenecientes a la familia lingüística otopame, de los cuales el otomí es el más numeroso y extendido (Carrasco 1979 [1950]; Soustelle 1993 [1937]). Los otomíes, aunque discriminados históricamente a raíz de la imagen negativa que de ellos difundieron otros grupos étnicos, en particular los mexica-tenochca, fueron parte del entorno político y social del centro de México por lo menos desde el Período Clásico (1-900 DC) (Wright 1995; Lastra 2006). Los otomíes no formaron una entidad política unificada, sus diversos gobernantes locales o caciques establecían alianzas entre sí y también con grupos de otras filiaciones 


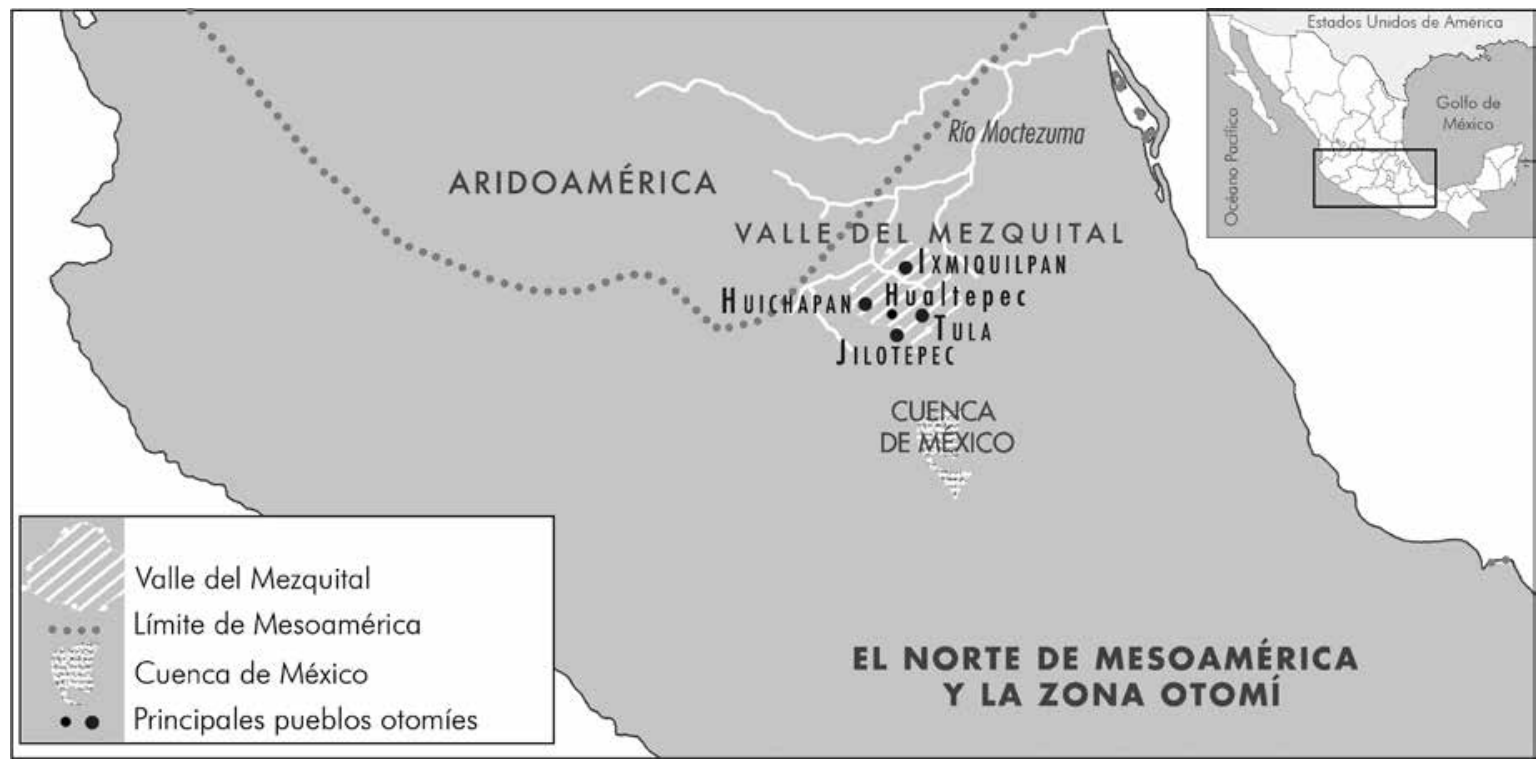

Figura 1. Mapa de localización del valle del Mezquital, México.

Figure 1. Map showing the location of the Mezquital Valley, Mexico.

étnicas y lingüísticas (Wright 1995). Sin embargo, es un hecho que los otomíes tuvieron una cultura mesoamericana, tanto en sus modos de subsistencia como en su cosmovisión (López Austin 2001).

Para algunos autores los otomíes fueron partícipes de la sociedad multiétnica que se desenvolvió en la gran urbe teotihuacana, a este respecto cabe mencionar que por lo menos desde 300 DC (López Aguilar 2005: 46). En términos que generan un mayor consenso, se acepta la presencia otomí en la ciudad Posclásica de Tula Xicocotitlan, la Tula legendaria de los Toltecas (900-1200 DC), la que se ubica en el sur del valle del Mezquital (Wright 1995, 2005; Mastache 2002). A partir de la caída de Tula ( $c a .1150$ DC), en el centro de México hubo una serie de reajustes políticos y territoriales por el control de las redes de intercambio anteriormente bajo el dominio de esta ciudad, y también por la penetración de grupos provenientes del norte aridoamericano, llamados genéricamente "chichimecas" (Carrasco 1979 [1950]: 241-271; Hers 1989). En este proceso los otomíes del valle del Mezquital continuaron como el grupo preponderante de la región; sus caciques establecieron pactos con las elites de la cuenca de México, en algunos casos otorgando tributos como se tiene documentado para los siglos $\mathrm{XV}$ y XVI (Brambila 2005: 24). En esta época de supremacía política y económica de los mexica-tenochca y sus aliados, el señorío de Jilotepec controlaba gran parte del occidente del Valle del Mezquital y ofrecía tributo a la capital mexica (Carrasco 1996: 42).
Posteriormente, durante la primera mitad del siglo Xvi los otomíes del valle del Mezquital apoyaron a los españoles durante la conquista del occidente de México (Wright 1994). En toda la región se levantaron enormes conjuntos conventuales que dan muestra de la labor evangelizadora y la expansión de la religión cristiana. Sin embargo, no se trató de una transición política pasiva por parte de los otomíes frente al poder colonial. Si se toma en cuenta el desenvolvimiento de los otomíes del valle del Mezquital desde la época prehispánica, es posible determinar que mantuvieron, y han mantenido hasta la actualidad, un control sobre su territorio, producto en gran medida de su capacidad de aliarse y negociar con las fuerzas hegemónicas en turno (Hers et al., 2014). En el plano religioso, durante el proceso de evangelización desarrollado por los frailes misioneros, los otomíes no aceptaron acrítica o pasivamente las nuevas ideas, sino que las asimilaron en el contexto de su propia forma de ver el mundo (Castillo 2004).

Los aspectos antes delineados en términos generales acerca de la historia y la cultura de los otomíes son de interés por dar un marco de referencia al estudio del arte rupestre. Control territorial, cosmovisión mesoamericana, vida ritual y pertenencia a un sistema de relaciones étnicas y políticas entre distintos grupos del centro de México son elementos que se vinculan con la elaboración y el sentido mismo del arte rupestre. ${ }^{3}$ Advertimos de antemano que en este devenir histórico tuvieron lugar distintas tradiciones pictóricas rupestres, 
no obstante lo que nos interesa en este trabajo es la tradición de pinturas blancas que por su iconografía puede fecharse entre los siglos XIV y XVII, grosso modo (Gress 2008).

\section{Arte rupestre y patrón de asentamiento}

El modo de vida tradicional de los otomíes tiende a la dispersión en pequeñas rancherías y la distribución de los sitios de arte rupestre sigue este mismo modelo, lo que dio lugar a una gran cantidad de conjuntos de tamaño variable a lo largo de las cañadas, probablemente cercanos a los sitios habitacionales que dejaron evidencias arqueológicas de distinto tipo (López Aguilar 1991). El arte rupestre parece haber sido un complemento bastante común de los asentamientos, junto con los manantiales, las milpas y el monte. A pesar de esa dispersión, la tradición pictórica de la cual nos ocuparemos aquí muestra una gran unidad que sugiere una vida ritual a nivel regional similar a la actual, en la que prevalecen intensos intercambios con las imágenes sagradas y los fieles que se visitan entre sí, de pueblo en pueblo (López Aguilar \& Fournier 2012).

La unidad de esa tradición se manifiesta en diversos rasgos como la ubicación de los sitios en las cañadas de ríos de temporal, el uso predominante de pintura blanca y la amplia presencia de motivos iconográficos relacionados con prácticas rituales y el pensamiento religioso. Los sitios de esta tradición comparten también los medios expresivos que utilizaron sus creadores y que analizaremos a continuación con ejemplos tomados de diversos conjuntos, como la ubicación en el paisaje, la inserción del soporte rocoso en el discurso pictórico, el color, el tamaño y las diferentes temáticas.

\section{El arte rupestre y espacio ritual otomí}

El arte rupestre del valle del Mezquital presenta una forma particular de emplazamiento dentro del paisaje que adquiere su plena significación si lo situamos en el ámbito del pensamiento mesoamericano en general y de las concepciones religiosas otomíes en particular. Los sitios con pintura blanca del valle del Mezquital se localizan, casi de manera exclusiva, en las cañadas que descienden de la principal elevación de la región, que consiste en una enorme caldera volcánica, denominada Hualtepec. Al borde de esta se levanta un cerro llamado actualmente Astillero y que parece haber sido nombrado originalmente Coatepec, es decir: "la montaña de las serpientes", lugar en donde nació Huitzilopochtli, el dios tutelar de los mexicas, de acuerdo con la tradición mítica e histórica recuperada en las fuentes escritas (figs. 2 y
3) (Alvarado Tezozómoc 1992 [1949]: 32-49; Gelo del Toro \& López Aguilar 1998: 72-76). Es sabido que los mexicas, antes de asentarse en la cuenca lacustre del centro de México, migraron durante varios años en esta zona, conviviendo de manera estrecha con los otomíes (Alvarado Tezózomoc 1992 [1949]: 31). En la cima del Coatepec se han encontrado vestigios arqueológicos que dan testimonio de un simbolismo semejante al que se desarrolló en el Templo Mayor de México-Tenochtitlan, nos referimos al complejo arquitectónico del templo doble y su vinculación con las deidades de la guerra y la lluvia, es decir, Huitzilopochtli y Tláloc (Gelo del Toro \& López Aguilar 1998: 67; López Austin \& López Luján 2009). (fig. 4).

En la actualidad, algunas poblaciones otomíes visitan la cumbre del cerro Coatepec durante la fiesta de la Santa Cruz el 3 de mayo, celebración que se vincula a la petición de lluvias y que constituye uno de los ejemplos más ilustrativos de la confluencia entre la religión cristiana y mesoamericana (Broda 2001; Albores 2003). Basados en los elementos anteriores nos formulamos la siguiente pregunta: ¿es lícito pensar que las cañadas en donde se encuentran las pinturas blancas fueron vistas como las serpientes que emergen del cerro sagrado? (fig. 5) La presencia en la iconografía misma de temas relacionados con este concepto, como imágenes de serpientes, de templos dobles, de guerra, de sacrificio y de culto a la fertilidad parecen indicar que sí. Estos motivos, como se verá más adelante, son, en efecto, algunos de los temas más recurrentes. Todos estos elementos permiten equiparar al Hualtepec con un axis mundi, un eje, a partir del cual el paisaje adquiere un orden compuesto por el dicho centro y las cañadas.

\section{Unidad e identidad a partir del color}

El primer contacto con el arte rupestre implica una experiencia sensorial, en la que todos nuestros sentidos son abstraídos y enfocados a buscar la forma de cada motivo expuesto en la roca. En este proceso el color es un elemento fundamental.

Los conjuntos de pinturas rupestres presentes en las cañadas del valle del Mezquital llaman la atención por su color blanco, el que contrasta con las superficies rocosas, muchas de las cuales son de tonalidades marrones y grisáceas. El blanco es un rasgo distintivo de una tradición pictórica extendida en toda la región, diferente de otras tradiciones aledañas geográficamente, como la pintura roja de Querétaro o las pinturas en rojo y negro que se diseminan en sitios del mismo valle del Mezquital, aunque en menor cantidad y presentando una menor unidad (Viramontes 2005; Gress 2008). 


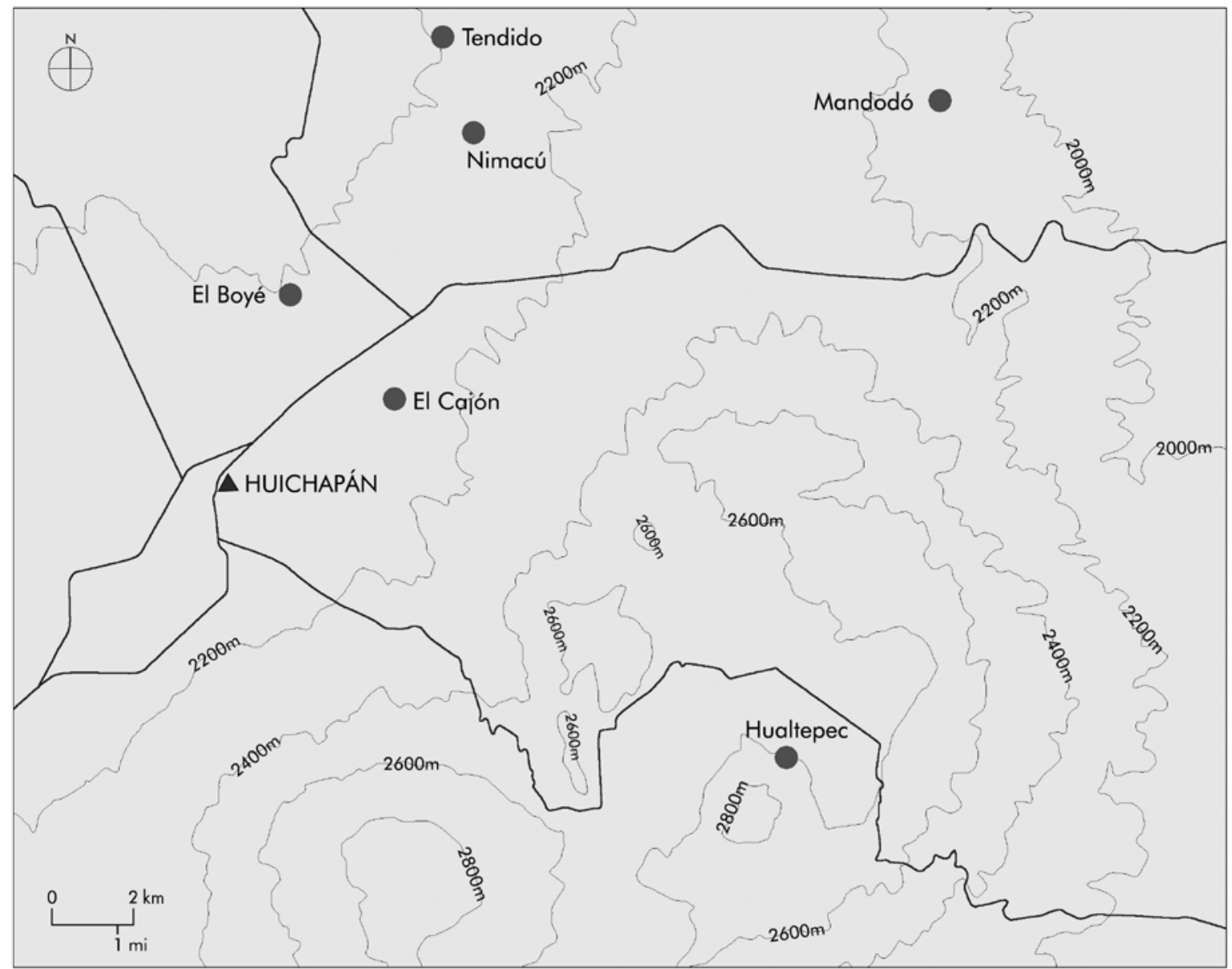

Figura 2. Área de distribución de los sitios con arte rupestre mencionados en este trabajo. Figure 2. Distribution of the rock art sites mentioned in the article.
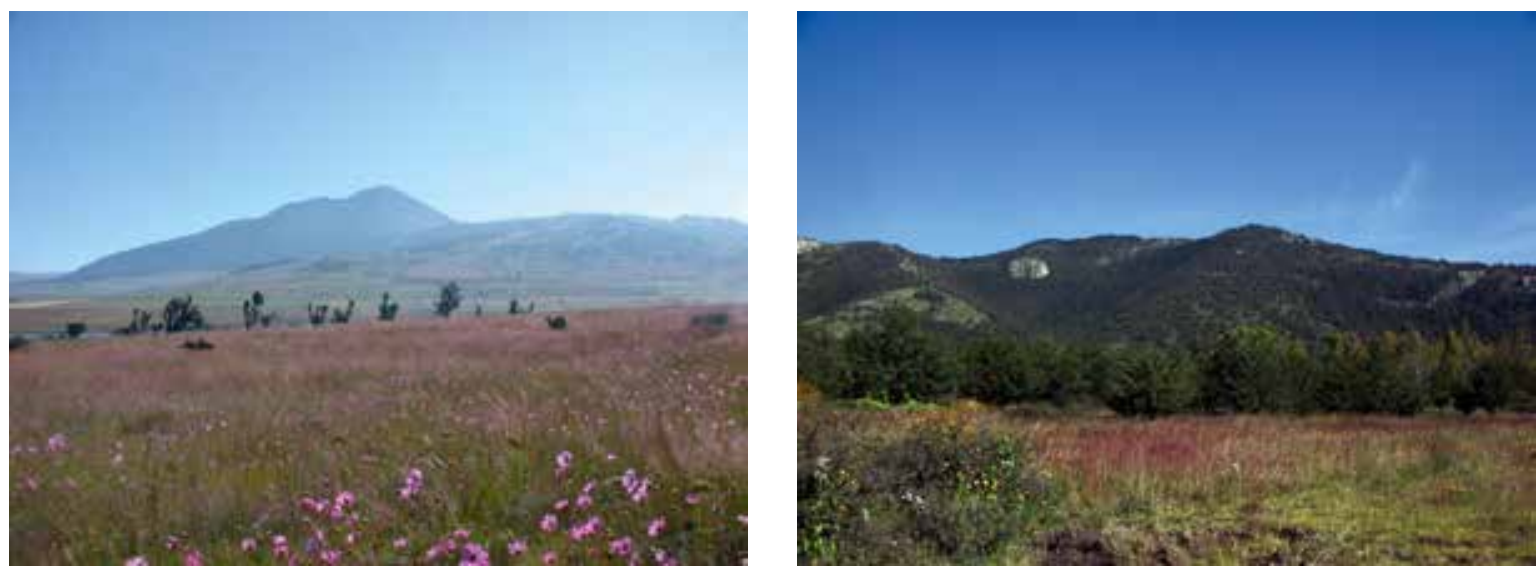

Figura 3. Vistas panorámicas del cerro Hualtepec, valle del Mezquital (foto del proyecto La mazorca y el niño Dios. El arte otomí: continuidad histórica y riqueza viva del Mezquital, UNAM).

Figure 3. Overviews of Cerro Hualtepec in the Mezquital Valley (photo from project La mazorca y el niño Dios. El arte otomi: continuidad histórica y riqueza viva del Mezquital, UNAM). 


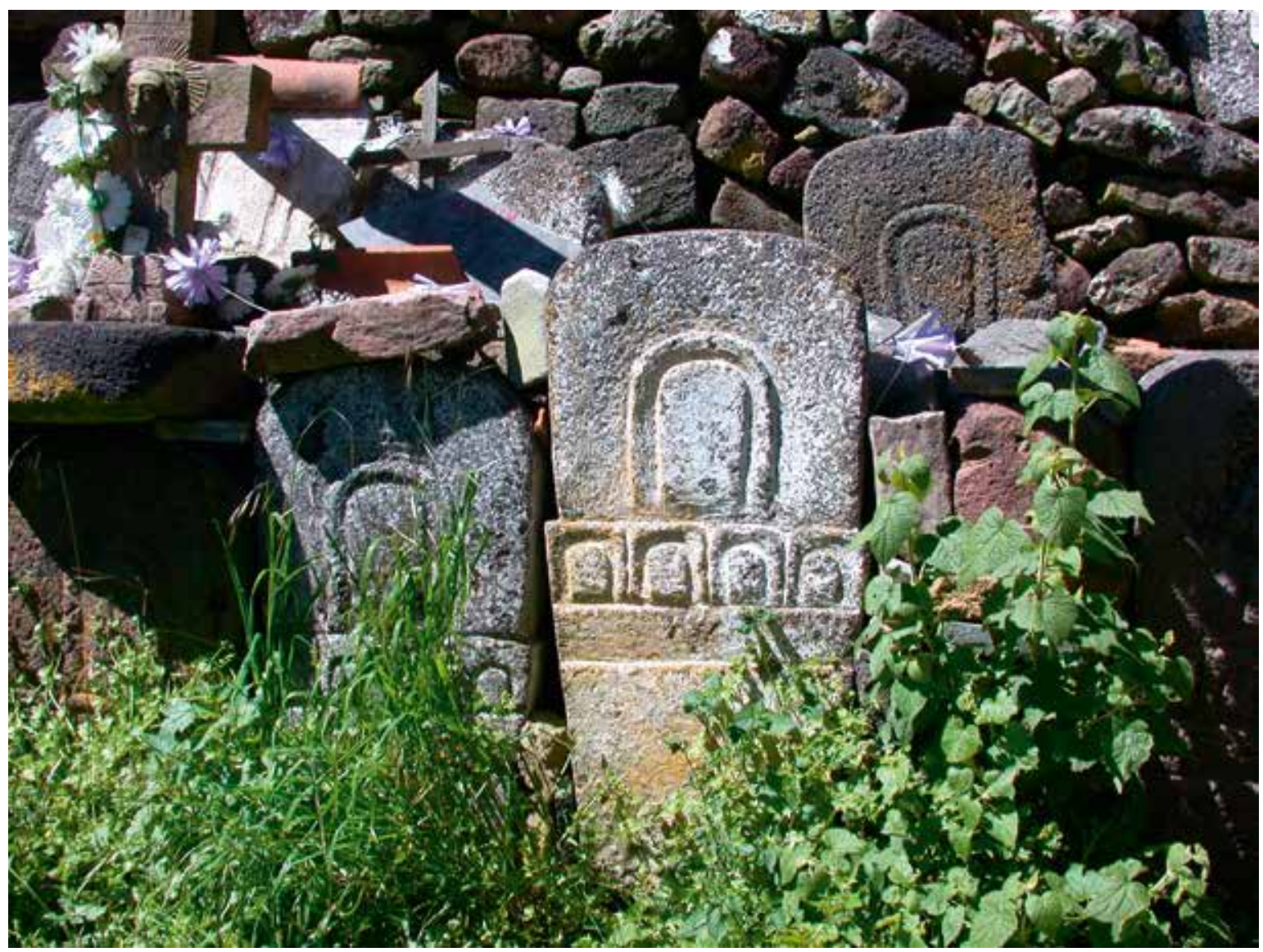

Figura 4. Lápidas encontradas en la cima del Hualtepec con diseños de plumas de águila, una advocación del dios Huitzilopochtli (foto del proyecto La mazorca y el niño Dios. El arte otomí: continuidad histórica y riqueza viva del Mezquital, UNAM).

Figure 4. Tombstones discovered at the summit of Hualtepec bearing eagle feather designs, an invocation to the god Huitzilopochtli (photo from project La mazorca y el niño Dios. El arte otomí: continuidad histórica y riqueza viva del Mezquital, UNAM).

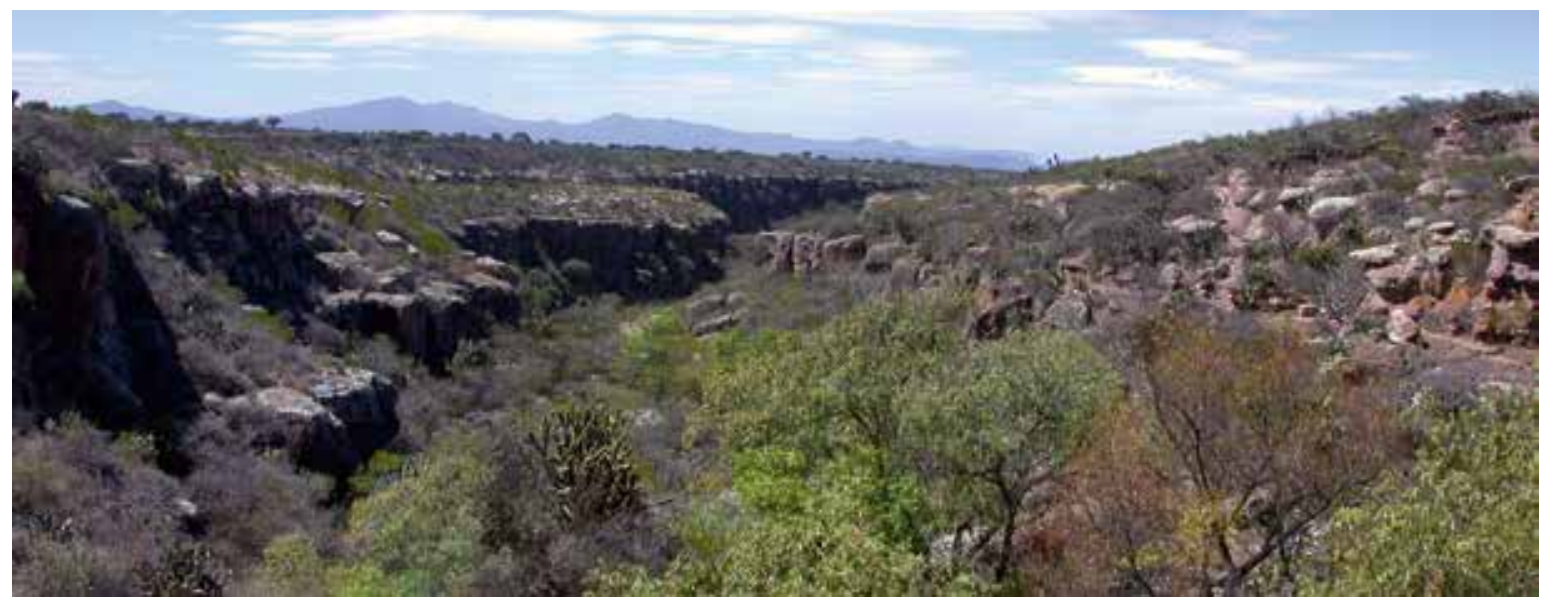

Figura 5. Vista general de la cañada Nimacú, municipio de Huichapan, estado de Hidalgo (foto del proyecto La mazorca y el niño Dios. El arte otomí: continuidad histórica y riqueza viva del Mezquital, UNAM).

Figure 5. Overview of the Nimacú ravine in Huichapan municipality, State of Hidalgo (photo from project La mazorca y el niño Dios. El arte otomi: continuidad histórica y riqueza viva del Mezquital, UNAM). 
El empleo preferencial del color blanco, posiblemente elaborado con un tipo de tierra blanca conocida en lengua otomí como hok'o y aglutinantes de origen vegetal o animal, refleja no solo un conocimiento técnico compartido por quienes prepararon estas pinturas, sino también una misma intencionalidad que se expresa pictóricamente por medio de este color (Luna, comunicación personal).

El contraste entre la pintura blanca y el color del fondo natural de la roca hizo posible que los motivos rupestres resaltaran ante el espectador, en algunos casos esto permitió que las pinturas fueran observadas desde la lejanía (fig. 6). El color blanco permaneció como una constante a pesar de la innovación en temáticas cristianas, que lejos de modificar el discurso de la barranca lo complementaron y dejaron de manifiesto la importancia del acto mismo de pintar. Por ello la presencia de repintes y superposiciones nos señalan el continuo uso de estos sitios como lugares de culto. Al mismo tiempo que se construían y pintaban los grandes conjuntos conventuales, la elaboración y resignificación del discurso rupestre continuaba vigente en las barrancas, las cuales no llegaron a perder su función de lugares para la actividad ritual.

No es posible determinar las implicaciones simbólicas que pudo tener el empleo del color blanco o si incluso los recursos materiales propios de la región influyeron en la consolidación de su uso, sin embargo, es clara su elección como un medio de expresión a nivel regional que perduró en el tiempo. La gran visibilidad que le otorga el blanco a las imágenes parece corresponder a la voluntad política que se expresa por medio de ese acto de pintar el paisaje, con temas que a primera vista subvierten el orden colonial (fig. 7). La elaboración de pinturas en donde elementos de la tradición cristiana, como las cruces o las iglesias, se encontraban al lado de motivos "paganos", como el templo sobre la pirámide o las escenas de sacrificio -realizadas todas en un mismo conjunto que por sus cualidades cromáticas se hacía evidente, en algunos casos a gran distancia- es una evidencia de la intención por reafirmar la apropiación de un territorio y de las nuevas ideas gestadas durante la Colonia.

\section{La barranca como escenario ritual}

La barranca es el espacio natural seleccionado con preponderancia para plasmar las pinturas rupestres; la manera en cómo fue empleada da muestra de distintas estrategias de expresión puestas en práctica. No es posible definir el comienzo o el fin de cada sitio, pues en ocasiones sus diversos motivos o conjuntos de pinturas rupestres no permanecen todos en un espacio continuo y algunos motivos suelen extenderse más allá de los conjuntos principales. Hemos apreciado que los espacios ubicados delante de los conjuntos pictóricos pueden ser amplios o exiguos, es decir, fueron pensados para albergar a muchos observadores o solo para contener unos pocos.

En el sitio de la barranca Nimacú hay una extensa zona que a manera de explanada permite la reunión de un grupo numeroso de personas al pie de una pared rocosa en donde fue pintada en lo alto la escena de un sacrificio humano dentro de un templo. Mientras tanto, en otra área del mismo sitio hay un gran conjunto de pinturas que solo puede ser observado por unos cuantos individuos debido a que el espacio delante de él es muy reducido. De este modo existe una forma diferenciada de concebir los espacios, donde el espectador aprecia de forma diferente las composiciones. Nimacú también tiene una particular característica, el acceso al sitio se realiza siguiendo un camino que las mismas pinturas sugieren, el que va desde la parte más alta exterior a la barranca misma, hasta la parte baja por donde retumba el agua entre grandes rocas. Este descenso está marcado por la presencia de una pintura que representa un enorme felino, posiblemente un jaguar, que fue plasmado en forma tridimensional por medio de su representación en la roca (fig. 8). En una parte aparece el rostro y en otra el cuerpo apenas sugerido por unos pocos trazos. Esta representación, en el ámbito de la cosmovisión mesoamericana, puede aludir al sol que baja al inframundo convertido en jaguar (Trejo 2004). De esta manera, el ingreso al sitio se convierte en un recorrido iniciático hacia un lugar sagrado en donde las pinturas mismas estarían indicando la presencia de númenes o entidades sobrenaturales.

A menudo se hace evidente que la forma misma de la roca sugiere la presencia de seres animados, como los antepasados o uemas, los cuales son enfatizados o cobran vida a partir de su exaltación por medio de la pintura rupestre. En efecto, un aspecto notable en esta tradición de la pintura blanca es el aprovechamiento de la configuración natural de la roca, pues en muchos casos tiene plena participación en el discurso pictórico. Por ejemplo en un farallón del sitio El Cajón podemos encontrar un hueco redondeado con unas fauces en su interior. En esta ejecución no solo la pintura es un objeto plástico, sino que la forma de la roca complementa el sentido de la composición, este recurso es eficaz para darle profundidad y vigor a la representación (fig. 9). Además la elección del lugar no es fortuita, pues el motivo se relaciona con diferentes significados: es el monstruo de la tierra que marca la entrada al inframundo, donde 


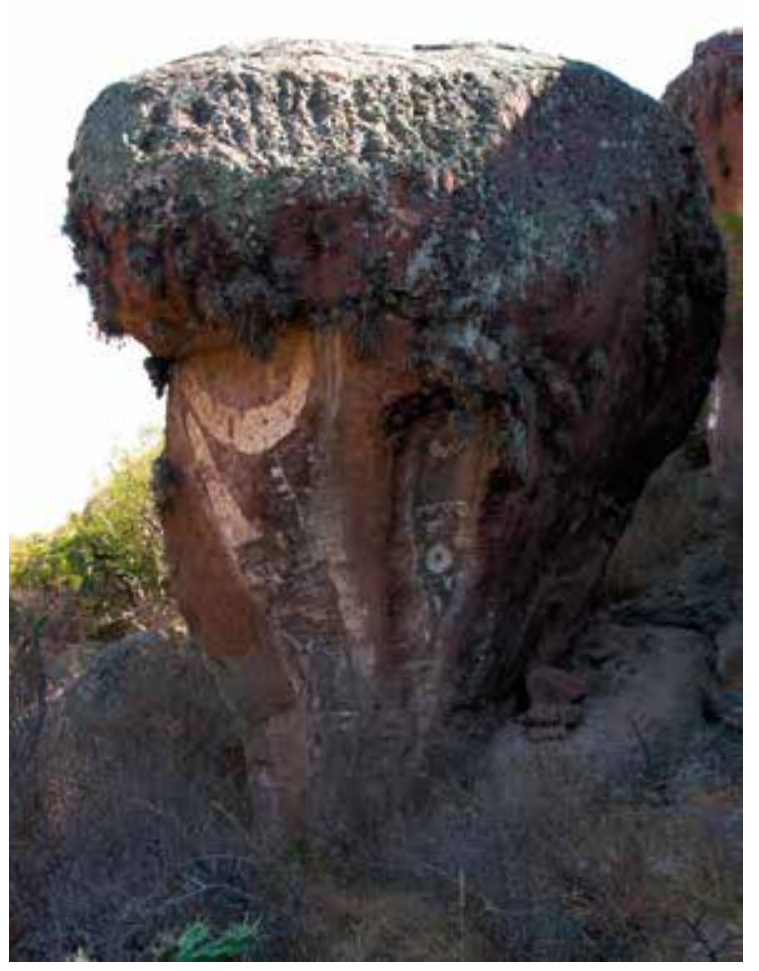

Figura 6. Conjunto pictórico en el sitio El Tendido, municipio de Huichapan, estado de Hidalgo (foto del proyecto La mazorca y el niño Dios. El arte otomí: continuidad histórica y riqueza viva del Mezquital, UNAM).

Figure 6. Group of pictures at the El Tendido site in Huichapan municipality, State of Hidalgo (photo from project La mazorca y el niño Dios. El arte otomi: continuidad histórica y riqueza viva del Mezquital, UNAM).

los muertos tienen un primer tránsito, es la morada de diversos dioses tanto de la muerte como de la fertilidad, es la entrada a las entrañas de la tierra también vinculada con la fertilidad y también es el ámbito de los antepasados o uemas (Heyden 1989; Luna, comunicación personal). Estos últimos se hacen presentes cuando, aprovechando una protuberancia de la roca, se pinta una cara. En el sitio El Cajón se encuentra el ejemplo de un uema pintado en lo más alto de una pared, el que ha sido completado por las mismas irregularidades en la roca. En este caso para representar una gran dimensión se utilizó tanto el tamaño como la altura, incluso se puede divisar desde lejos (Hernández 2013).

Los motivos celestes como soles, lunas en cuarto creciente o cielos estrellados son otros de los temas recurrentes (fig. 6). La mayor parte de las representaciones celestes suelen situarse sobre los techos de abrigos rocosos, quedando por encima de la cabeza del espectador, lo que enfatiza su papel como astros que se ubican en el firmamento. También aparecen acompañados de animales mitológicos que en el mundo mesoamericano están asociados con ellos, como el venado, el conejo o la serpiente.

En distintos sitios se observan varios ejemplos de cielos con estrellas, los cuales fueron plasmados en los techos. De esta manera, la ubicación espacial se usó para recrear la bóveda celeste; es el espacio sagrado donde transitan las deidades como el sol, la luna y Bok'yä.

\section{Las imágenes en la barranca La elocuencia del tamaño}

Los motivos del arte rupestre de la pintura blanca del Valle del Mezquital son de diferentes tamaños, los cuales van desde figuras pequeñas de apenas $10 \mathrm{~cm}$ hasta algunas de más de un metro (fig. 10). Estas variaciones juegan un papel importante en la composición de los conjuntos pictóricos. Las diferentes dimensiones en un mismo conjunto pueden responder a la necesidad de resaltar algunos de ellos en particular, dentro de escenas narrativas vinculadas a actividades rituales. Los de mayor tamaño suelen ocupar espacios preferenciales en las composiciones y son los primeros que atraen la atención del observador, esto hace pensar en una jerarquización que estuvo relacionada con la significación de los paneles en su conjunto.

En un conjunto pictórico del sitio Mandodó sobresalen dos grandes personajes que flanquean otros motivos de menor tamaño (fig. 7). En la exégesis de los pobladores actuales han sido interpretados como antepasados o uemas, gigantes que habitaron la tierra en una era anterior y a quienes se les atribuye ser los constructores de las iglesias, entre otras acciones (Sánchez 2004; Avilés 2008: 55; Luna, comunicación personal).

Otro caso significativo es la representación de un jinete de grandes dimensiones en el sitio El Cajón, aparentemente aislado. Su presencia en la barranca nos recuerda la importancia tanto del caballo como los caciques otomíes, quienes obtuvieron distintos privilegios al fungir como aliados de la Corona española (Wright 1988; Hernández 2013). Este recurso parece reafirmar el papel político del arte rupestre, enfatizado por la presencia de escudos.

\section{La Bok'yä y el sacrificio}

Entre los distintos temas que están presentes en la tradición de pintura blanca destacan dos que son complementarios entre sí: la serpiente de lluvia y el sacrificio, mismos que constituyen la razón de ser de este arte rupestre. Ambos expresan un pensamiento religioso que gira 


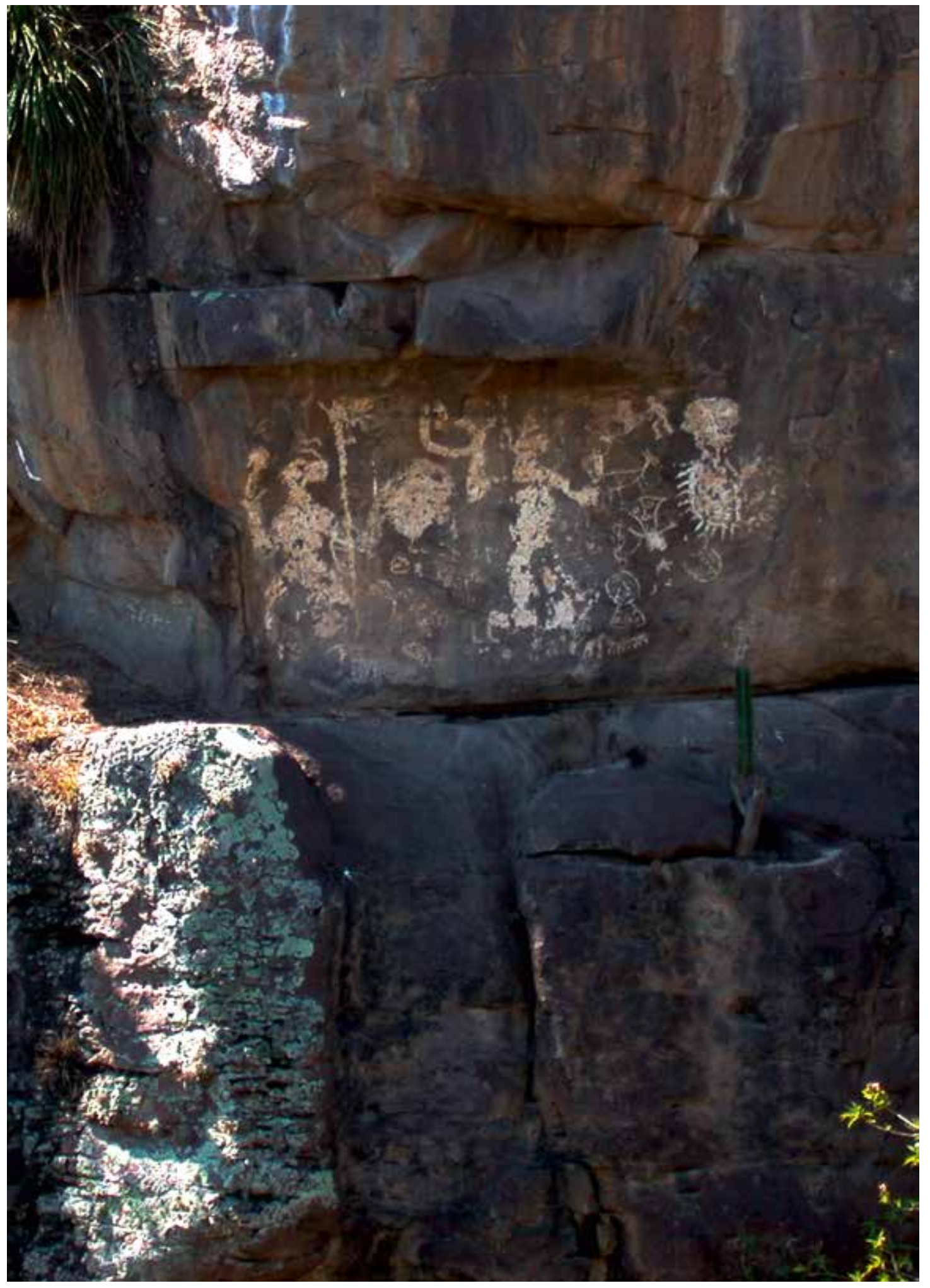

Figura 7. Vista a distancia de uno de los conjuntos pictóricos del sitio Mandodó, municipio de Alfajayucan, estado de Hidalgo (foto del proyecto La mazorca y el niño Dios. El arte otomí: continuidad histórica y riqueza viva del Mezquital, UNAM).

Figure 7. Wide view of one of the pictorial groups at the Mandodó site in Alfajayucan municipality, State of Hidalgo (photo from project La mazorca y el niño Dios. El arte otomí: continuidad histórica y riqueza viva del Mezquital, UNAM). 

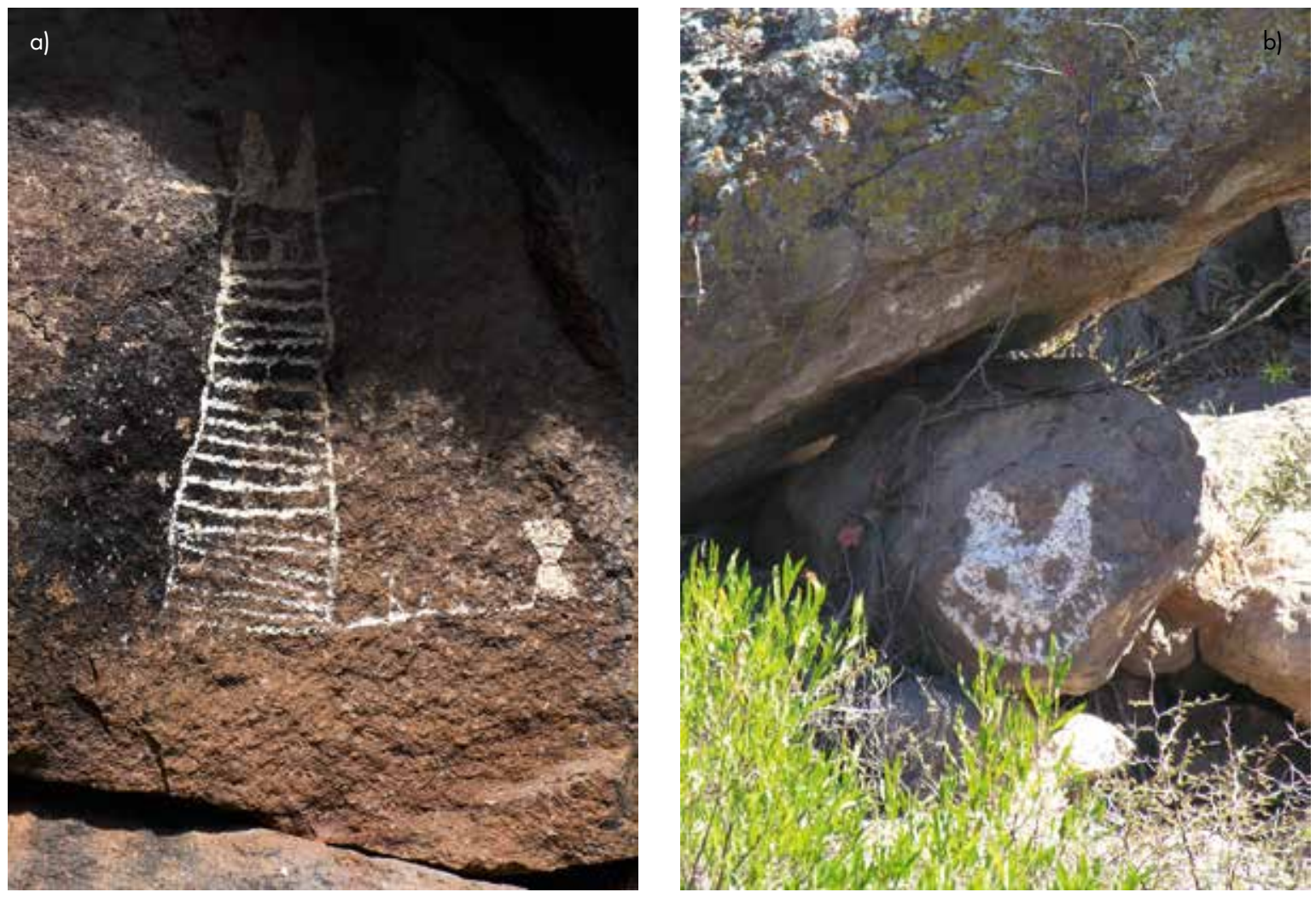

Figura 8. Escenas de sacrificio en el interior de un templo y jaguar, sitio Nimacú, estado de Hidalgo (foto del proyecto La mazorca y el niño Dios. El arte otomí: continuidad histórica y riqueza viva del Mezquital, UNAM).

Figure 8. Scenes of sacrifice inside a temple and jaguar, at Nimacú site, State of Hidalgo (photo from project La mazorca y el niño Dios. El arte otomi: continuidad histórica y riqueza viva del Mezquital, UNAM).

alrededor de la reciprocidad entre los dones divinos y el sacrificio del hombre.

El motivo de la serpiente de lluvia o Bok'yä consiste en una banda horizontal dividida en su interior por una retícula romboidal o triangular, del que penden elementos colgantes; a simple vista se trata solo de un diseño geométrico (fig. 11). Altamente esquemático y uniforme en sus distintas representaciones, este motivo pudo haber pasado inadvertido a no ser por su alta frecuencia. No obstante, a partir de una atenta observación de sus variantes se ha logrado identificar como una representación de la llamada serpiente de lluvia o Bok'yä, un numen otomí que forma parte de la cosmogonía mesoamericana que gira en torno a la creencia en una serpiente celeste cargada con el agua de lluvia. En ocasiones los elementos colgantes son claramente identificables como representaciones de ollas u odres, que en determinadas épocas del año vierten el líquido vital sobre la superficie de la tierra (Valdovinos 2009). La indagación sobre este numen fue un proceso importante, ya que constituye uno de los temas centrales de esta tradición pictórica rupestre, vinculada a la petición de lluvias. Además se ubica en prácticamente todos los sitios y su disposición sobre diferentes planos de la roca sugiere su presencia en distintos ámbitos cósmicos (cielo, tierra, inframundo).

En esta tradición el sacrificio se expresa de distintas maneras: el sacrificio en el templo, el sacrificio del venado o de las garzas y el de Cristo mismo. Los basamentos piramidales, en algunos casos coronados por templos dobles característicos del Período Posclásico Tardío, ocupan un papel preponderante en varios sitios (figs. 6 y 8). Las variaciones formales en las representaciones de arquitectura son muchas: en ocasiones aparecen de perfil, a veces de frente, en otras solo se representan las escalinatas, y las diferencias en la techumbre también son evidentes. Sin embargo, el tema persiste de manera constante y remite al significado religioso de las pinturas mediante escenas de sacrificio, las cuales se aprecian en el interior de los templos, en donde se observa a la víctima recostada sobre la piedra sacrificial sostenida por los oficiantes (fig. 8). 

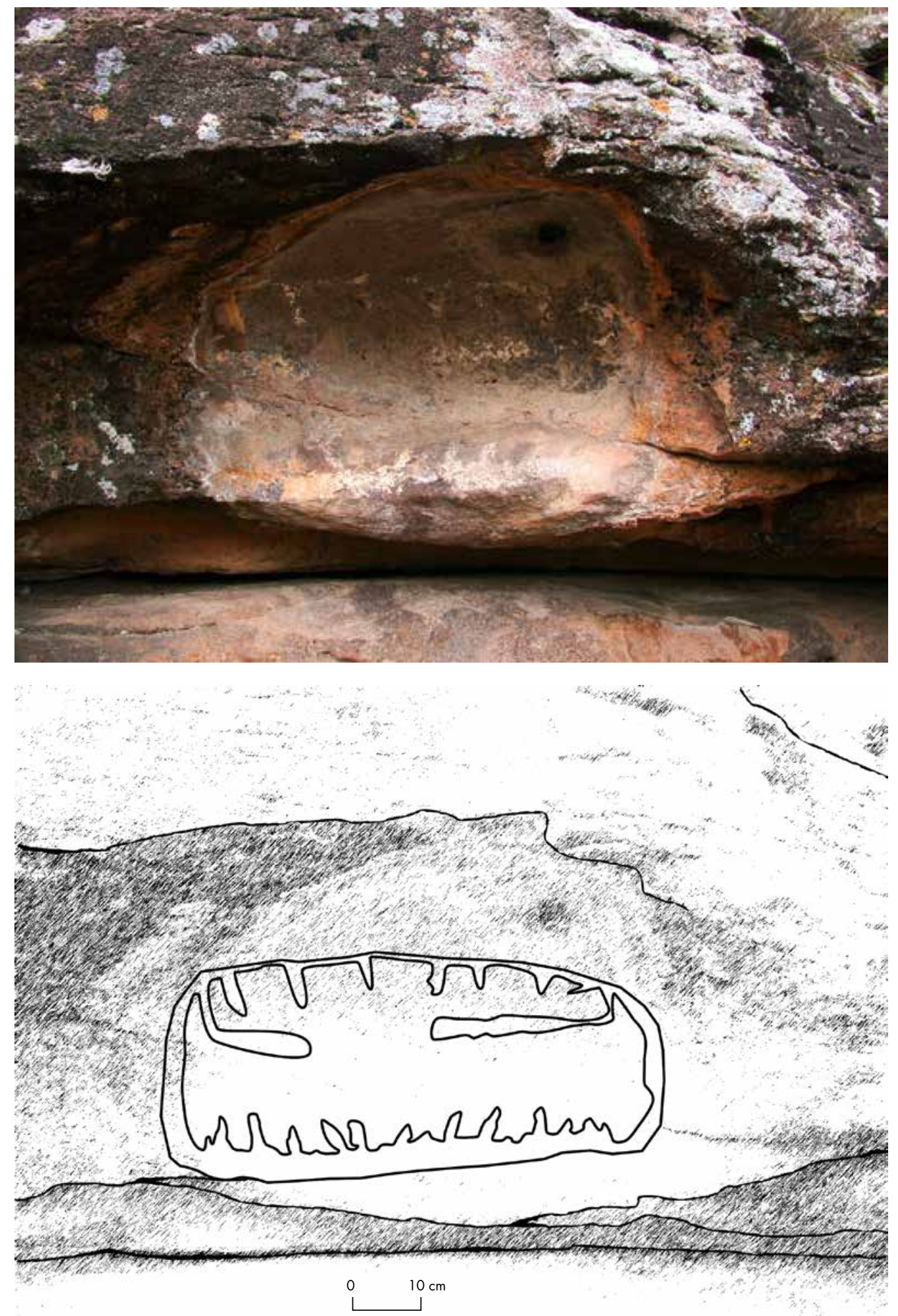

Figura 9. Detalle de Las fauces, sitio El Cajón, municipio de Huichapan, estado de Hidalgo (foto del proyecto La mazorca y el niño Dios. El arte otomí: continuidad histórica y riqueza viva del Mezquital, UNAM).

Figure 9. Detail of Las Fauces, at El Cajón site, in Huichapan municipality, State of Hidalgo (photo from project La mazorca y el niño Dios. El arte otomí: continuidad histórica y riqueza viva del Mezquital, UNAM). 


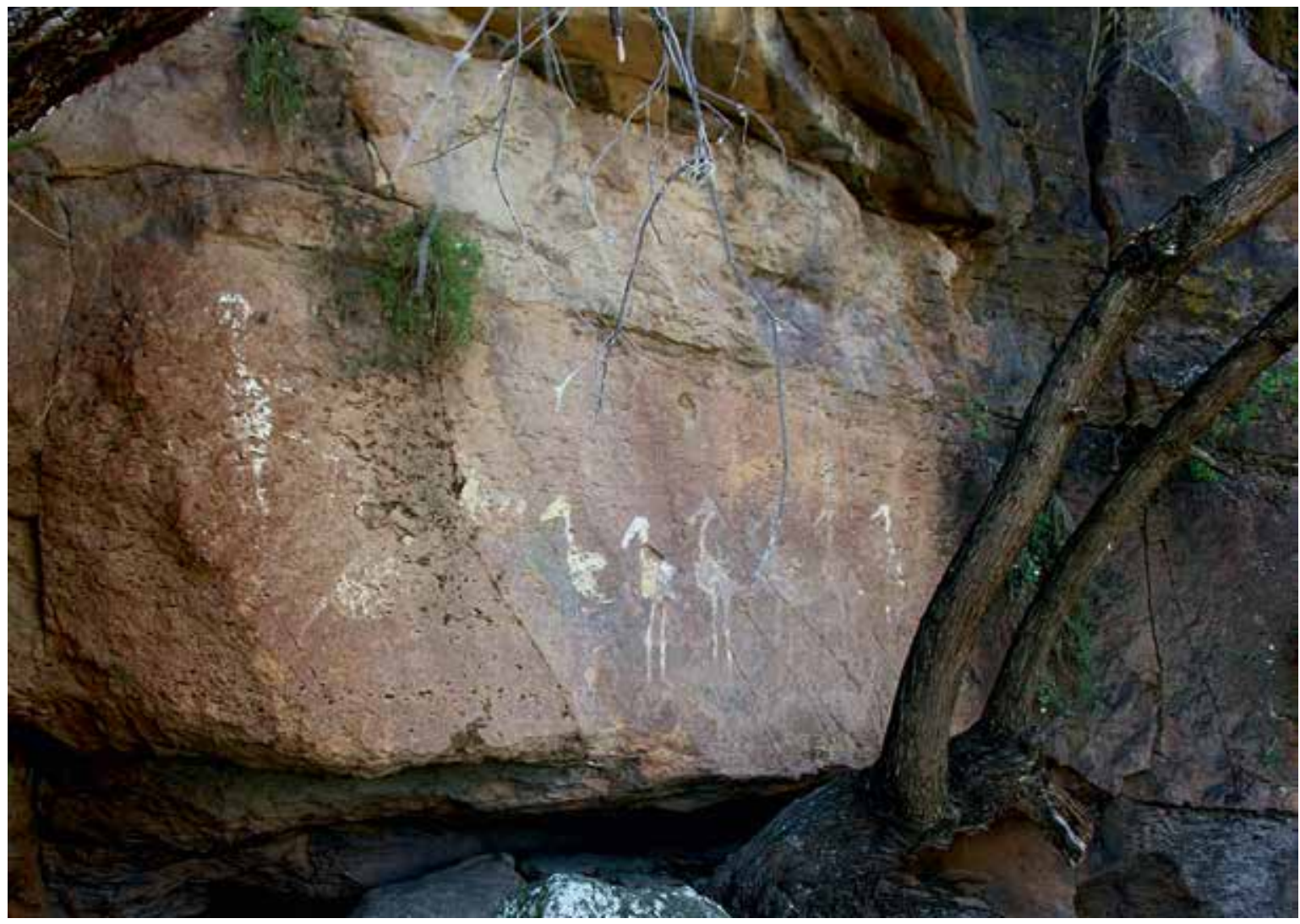

Figura 10. Garzas flechadas sitio El Boyé, municipio de Huichapan, estado de Hidalgo (foto del proyecto La mazorca y el niño Dios. El arte otomí: continuidad histórica y riqueza viva del Mezquital, UNAM).

Figure 10. Herons shot with arrows, El Boyé site in Huichapan municipality, State of Hidalgo (photo from project La mazorca y el niño Dios. El arte otomi: continuidad histórica y riqueza viva del Mezquital, UNAM).

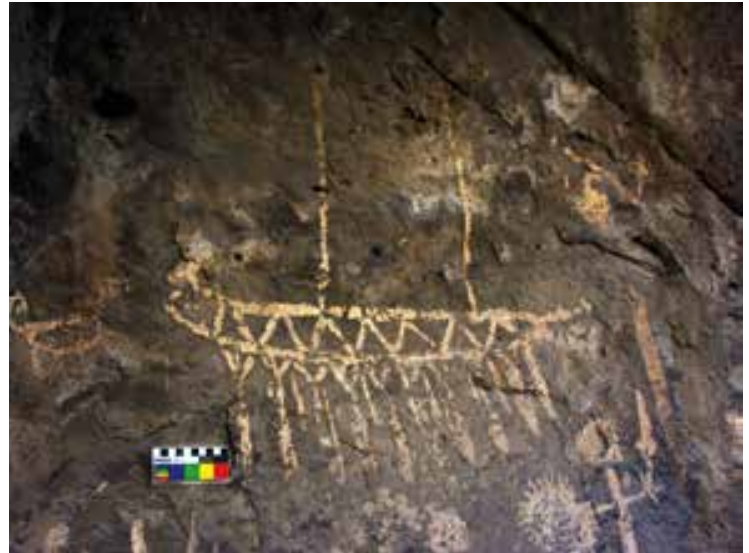

Figura 11. Representación de "serpiente de agua" o Bok'yä, sitio El Tendido, estado de Hidalgo (foto del proyecto La mazorca y el niño Dios. El arte otomí: continuidad histórica y riqueza viva del Mezquital, UNAM).

Figure 11. Representation of Bok'yä ("water snake") at El Tendido site, State of Hidalgo (photo from the project La mazorca y el niño Dios. El arte otomí continuidad histórica y riqueza viva del Mezquital, UNAM).
Otra evocación del sacrificio es la cacería del venado, la que se encuentra en la mayoría de los sitios (fig. 12). La representación formal de esta escena, en donde aparecen uno o varios animales con cornamenta y cuerpo moteado, así como personajes con arco y flecha, tiene una transparencia icónica que no deja lugar a dudas sobre el acto realizado. No obstante sus implicaciones simbólicas van más allá de este hecho. Después de estudiar las tradiciones míticas otomíes, nos inclinamos a pensar que se trata de una representación del sacrificio del venado, por medio del cual se recrea la muerte sacrificial del primer venado en el origen del tiempo, el cual es visto como el antepasado y hermano mayor de los otomíes, también conocido como Makunda (Luna, comunicación personal).

Suele haber casos excepcionales en donde en lugar de venados aparecen garzas, como es el caso del sitio de El Boyé. En este lugar el artífice supo aprovechar con maestría la configuración del soporte rocoso. La amplitud de la roca le permitió dar gran tamaño a las 


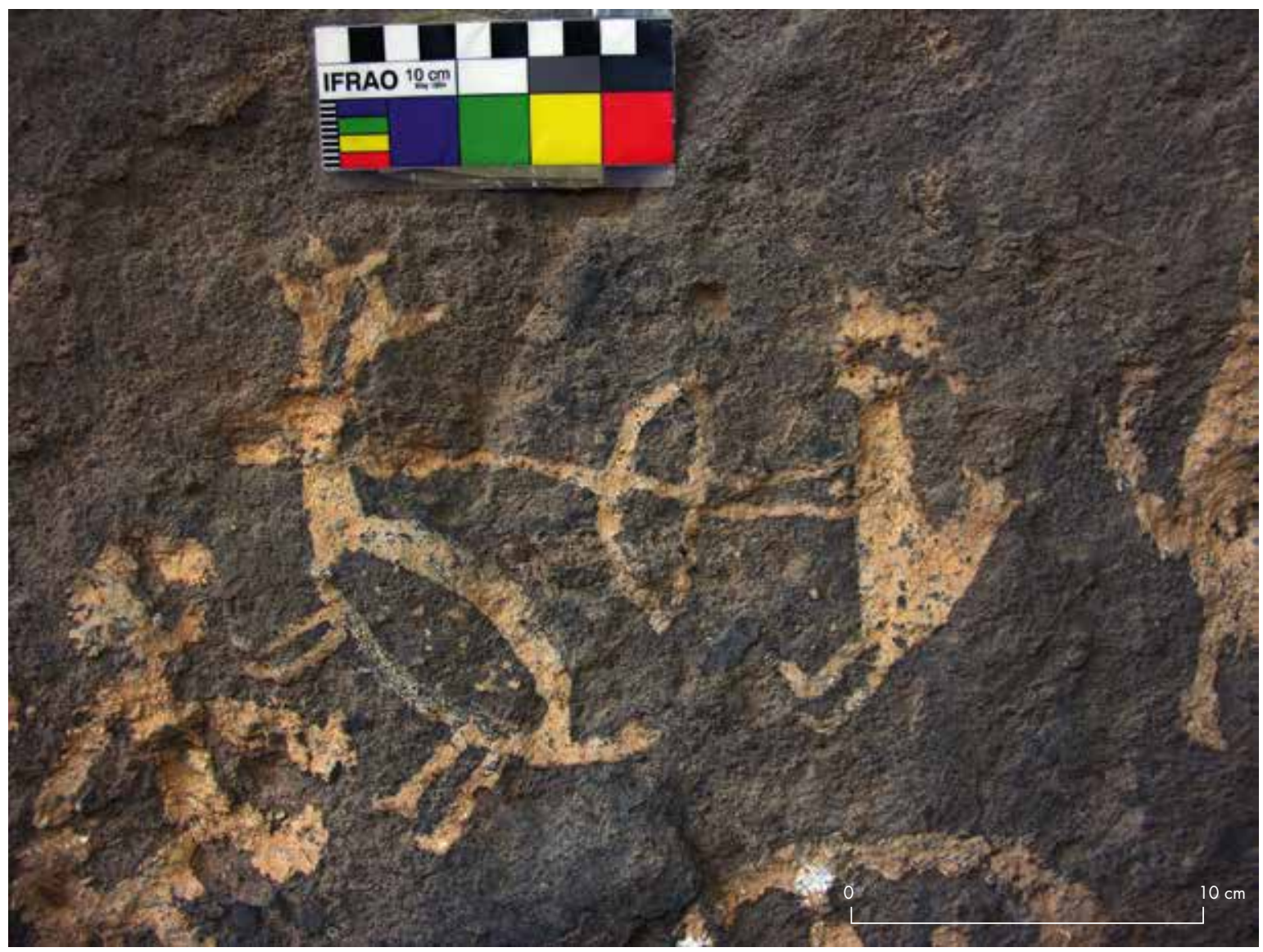

Figura 12. Venado flechado, sitio de Nimacú, municipio de Huichapan, estado de Hidalgo (foto del proyecto La mazorca y el niño Dios. El arte otomí: continuidad histórica y riqueza viva del Mezquital, UNAM).

Figure 12. Deer shot with arrow at Nimacú site in Huichapan municipality, State of Hidalgo (photo from project La mazorca y el niño Dios. El arte otomí: continuidad histórica y riqueza viva del Mezquital, UNAM).

figuras, lo que le dio una notable presencia al conjunto que puede verse desde lejos y que incluso se refleja en el estanque de agua que se extiende al pie de las aves.

En el primer plano se identifica una hilera de seis garzas vistas de perfil. La fisonomía, el color y forma sugieren que el artista plasmó a las garzas en su forma real. Las garzas se diferencian entre sí por el tamaño y el movimiento del cuello, pareciera que el pintor quisiera plasmar el momento mismo en que la parvada inquieta percibe la presencia de un perro que asoma la cabeza en el extremo izquierdo de la escena. En efecto, no parece ser un azar que el pintor ubicara al perro en dos planos contiguos: su cabeza en el de las garzas y el cuerpo sentado en el del cazador que por la configuración de la roca quedaría escondido de las aves (fig. 10).

En El Boyé las garzas son flechadas por el cazador, sustituyendo al venado en su sacrificio. En cuanto a ejecución, este conjunto contrasta por la fuerza de sus medios expresivos con el carácter eminentemente codificado de la escena del flechamiento del venado. Esto podría corresponder a una libertad de expresión correspondiente a una etapa más tardía, ya avanzado el periodo colonial (Peña 2014).

\section{La presencia colonial en el arte rupestre}

Los cambios que arribaron con la conquista y la religión cristiana dieron un viraje al tema del sacrificio. El rostro de Cristo como nuevo símbolo religioso y del sacrificio también se encuentra representado (fig. 13). En este ejemplo destaca la similitud que presenta el rostro con las imágenes de los catecismos llamados testerianos, los cuales fueron recursos de escritura pictográfica desarrollados por los frailes evangelizadores para promover la nueva religión (Lara 2008). El detalle en los rasgos de la cara escapa a los cánones de la tradición prehispánica, 

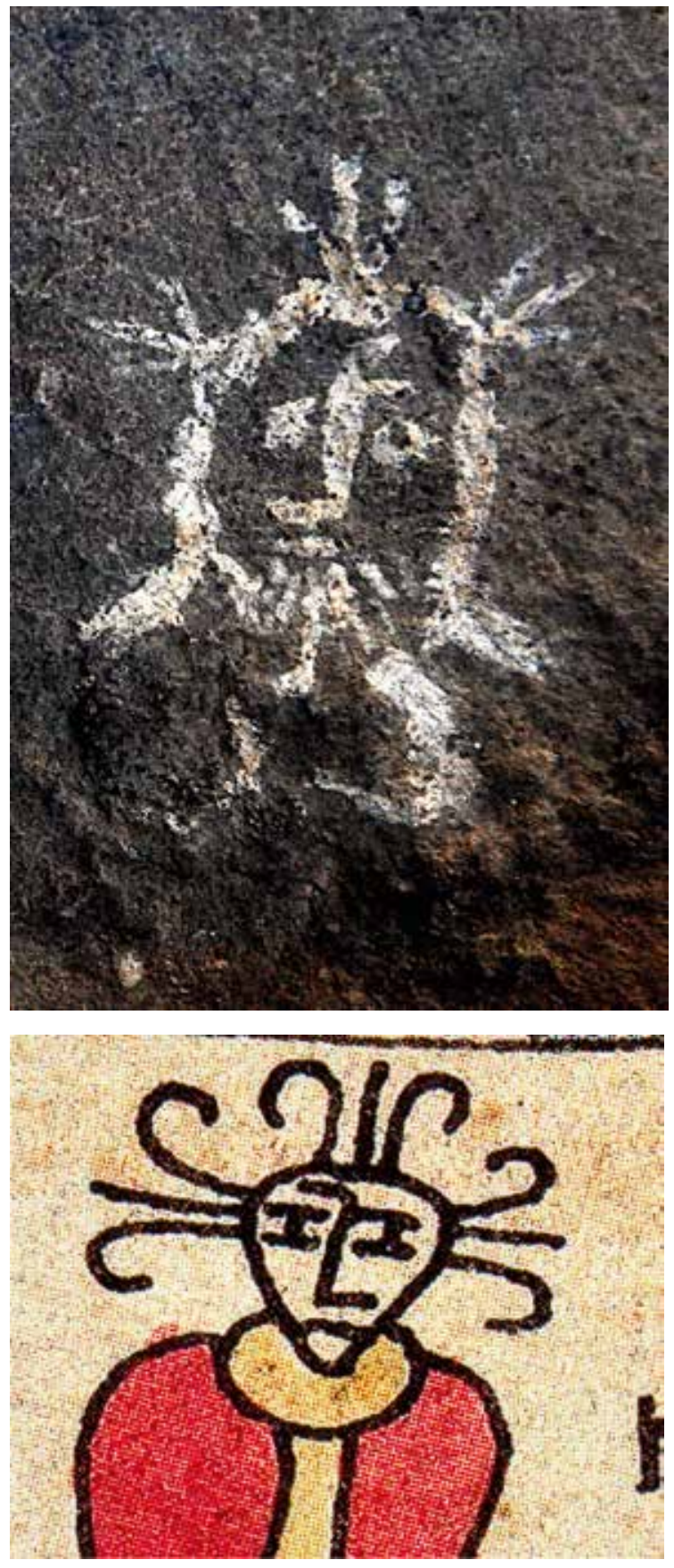

Figura 13. El Rostro de Cristo, sitio El Cajón y Cristo con las tres potencias, en catecismo Testeriano (foto del proyecto La mazorca y el niño Dios. El arte otomí: continuidad histórica y riqueza viva del Mezquital, UNAM).

Figure 13. Face of Christ, El Cajón site, and Christ with the Three Powers, from the Testerian Catechism (photo from project La mazorca y el niño Dios. El arte otomi: continuidad histórica y riqueza viva del Mezquital, UNAM). pero el formato y el color se conservan, así como la necesidad de enunciar el contenido mediante el discurso rupestre. Además, el rostro de Cristo aparece en un lugar prácticamente invisible, pues fue hecho sobre un pequeño techo cuya altura es mínima respecto del piso. Pareciera que es el carácter de imagen especialmente sagrada lo que motivó que su realizador lo plasmara en este oculto lugar, al tiempo que su ubicación sobre un techo remite a su carácter celestial. Completan esta composición la presencia de la serpiente sagrada y el venado, subrayando la plena inserción del sacrificio de Cristo dentro del pensamiento religioso otomí.

Más común como expresión de la adopción y adaptación de la religión cristiana al pensamiento tradicional es la presencia frecuente del tema de la arquitectura religiosa. Elementos como el campanario o los portales de los claustros acapararon la atención de los pintores, en algunos ejemplos se evocó el sonido de los nuevos tiempos de la Colonia por medio de la representación de un personaje que tañe las campanas. La frecuente presencia de esta arquitectura colonial en el arte rupestre nos indica que para la población indígena de la región estas construcciones, lejos de representar la imposición unilateral de la religión cristiana y del sometimiento de los indígenas a ella, fueron el resultado de una intensa negociación entre las órdenes evangelizadoras y los líderes indígenas, lo que a menudo significó el prestigio de los pueblos en donde se levantaron las nuevas edificaciones.

\section{A MANERA DE CONCLUSIÓN}

Proponemos realizar un acercamiento a detalle de dos conjuntos particularmente representativos de los logros expresivos alcanzados por los pintores de la tradición blanca.

Un conjunto que da cuenta de varios de los aspectos que hemos tratado en el texto es La Danza ubicada en El Boyé. Se encuentra en un abrigo en forma de hemiciclo cuyo techo tiene dos niveles (fig. 14). Uno en forma semicircular fue aprovechado para disponer una fila de danzantes con los brazos entrelazados. El friso superior es recto y presenta a la Bok'yä en forma de banda reticulada, mientras en la parte baja la serpiente es representada con ollas u odres y colgajos. Desde lo alto, la danza de la sagrada serpiente preside escenas propias del calendario agrícola: el ciclo lunar, y rituales relacionados con la fertilidad y petición de lluvia.

Las imágenes son visibles a gran distancia y tienen un dinamismo marcado por los frisos naturales que crean un impacto para el observador (Peña 2014). Abajo se 


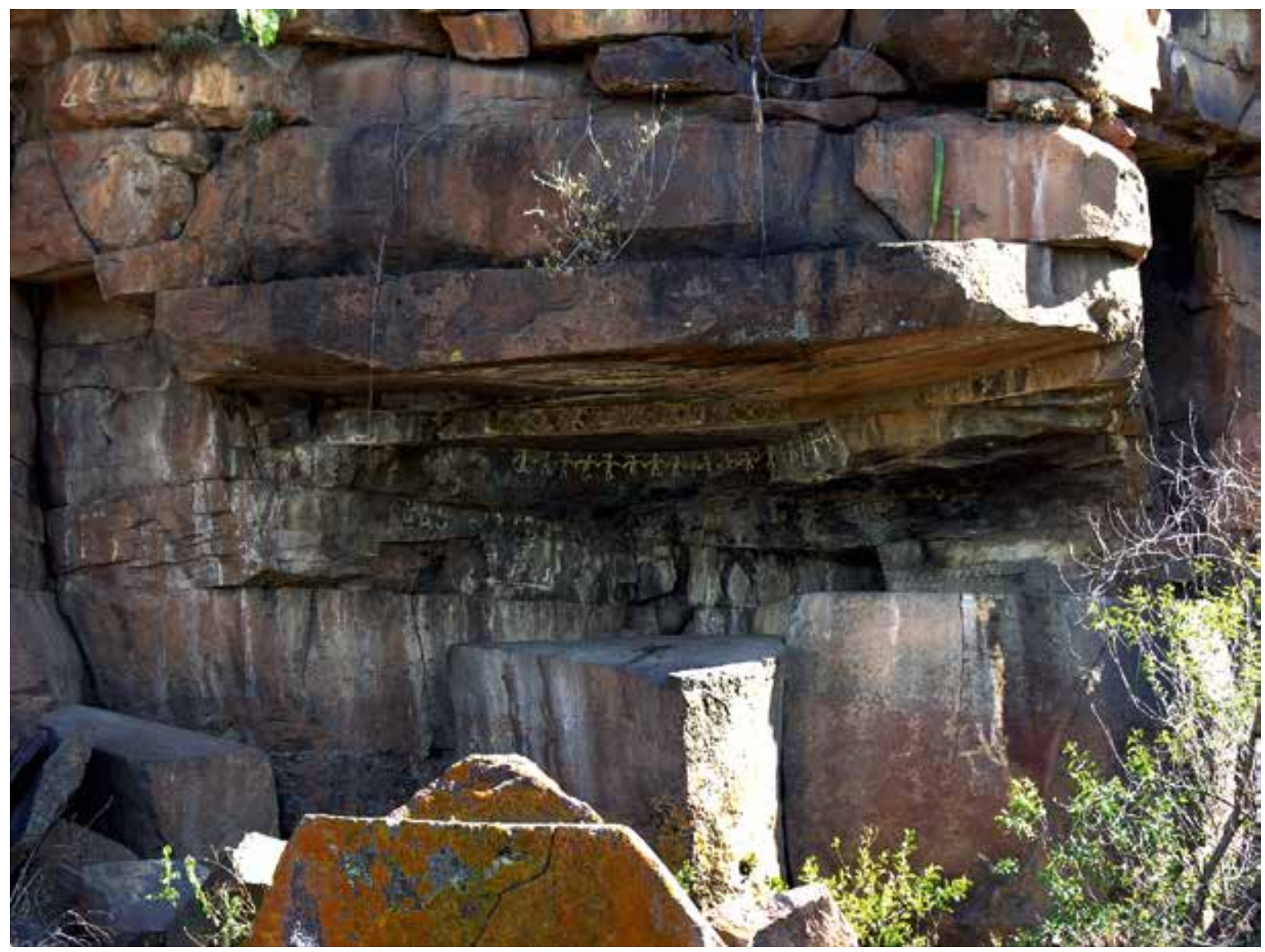

Figura 14. La danza sitio El Boyé, municipio de Huichapan, estado de Hidalgo (foto del proyecto La mazorca y el niño Dios. El arte otomí: continuidad histórica y riqueza viva del Mezquital, UNAM).

Figure 14. "The dance," from El Boyé site in Huichapan municipality, State of Hidalgo (photo from project La mazorca y el niño Dios. El arte otomi: continuidad histórica y riqueza viva del Mezquital, UNAM).

encuentra un friso en donde aparece la representación de garzas asociadas con la serpiente, reiterando de esta manera el vínculo indisoluble entre sacrificio y la fertilidad (fig. 14).

El conjunto principal del sitio El Tendido resume muchos de los aspectos señalados (fig. 15), su composición responde a una compleja relación entre elementos iconográficos de tradición mesoamericana y cristiana, que parecen responder a una interpretación de diversos elementos provenientes de estos dos ámbitos. Los casos más evidentes en este sentido son la presencia del templo piramidal y de la iglesia cristiana. El panel parece haber sido concebido como una unidad formada por dos espacios principales, uno en la parte superior alude a temas de la ritualidad mesoamericana, en él se ubican dos enormes montículos piramidales coronados por templos, en tanto que en la parte inferior destaca la representación de una iglesia conventual en donde incluso se representó el pórtico del convento.
Por medio de los templos prehispánicos se alude al tema del sacrificio humano y al ritual, el que es enfatizado por una procesión que sale de un palacio almenado ubicado a la derecha de la composición; los personajes llevan elementos en las manos que parecen aludir a sonajas o algún instrumento musical similar. En un formato mayor y como perteneciente a un momento posterior de ejecución, vemos un gran personaje en medio de los dos templos que por su posición horizontal y ubicado sobre un elemento que cumple las veces de piedra sacrificial. Más a la derecha hay un enfrentamiento entre un personaje a caballo y otro a pie, si bien esto puede ser interpretado como la escenificación de una guerra de conquista, también puede aludir a los rituales que en la actualidad se realizan en el contexto del carnaval, como es el caso de la comunidad de Bají, actual municipio de Tecozautla. En este último lugar se recrea un combate ritual entre dos bandos en donde un hombre a caballo y uno de a pie encabezan dos bandos que se 


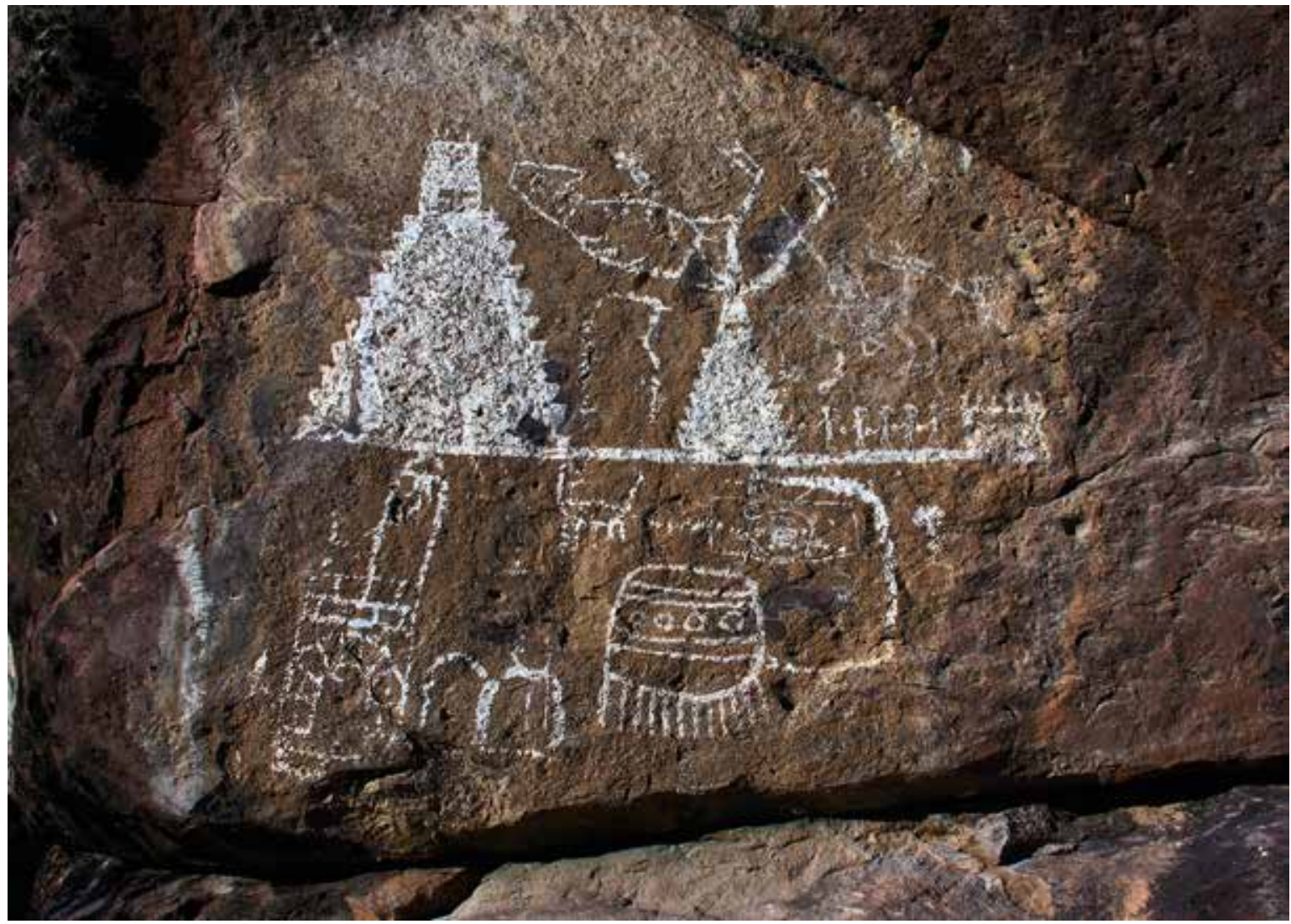

Figura 15. Conjunto principal del sitio El Tendido, Huichapan, estado de Hidalgo (foto del proyecto La mazorca y el niño Dios. El arte otomí: continuidad histórica y riqueza viva del Mezquital, UNAM).

Figure 15. Central grouping of El Tendido site, Huichapan, State of Hidalgo (photo from project La mazorca y el niño Dios. El arte otomí continuidad histórica y riqueza viva del Mezquital, UNAM).

enfrentan durante dos días; este enfrentamiento ritual termina con el sacrificio de uno de ellos.

En la parte inferior del panel, además de la iglesia ya mencionada, hay una imagen de un escudo, lo que podría ser una referencia a una comunidad, y la imagen de un venado unido a un elemento geométrico cuadrangular. Por su forma se reconoce el característico venado de cuerpo moteado que se repite en todos los sitios de esta tradición pictórica. La amplia visibilidad de este conjunto y su temática descrita, sintetiza varios de los aspectos comentados a lo largo del trabajo.

Nuestra intención ha sido mostrar cómo por medio de la identificación de una serie de recursos expresivos, de su contextualización histórica y con apoyo de la tradición oral es posible generar una interpretación verosímil para la comprensión de este arte rupestre. Hemos podido ejemplificar algunos elementos de este arte rupestre en los cuales se percibe la intención de construir un discurso propio con imágenes de tradiciones diferentes que les permitiera conservar su cosmovisión, donde el ritual religioso, en particular el sacrificio para la Bok'yä, era esencial.

Este arte rupestre del Mezquital encuentra unidad a través de un espacio ordenado (el centro y las cañadas) y de la complementación, pues el corpus iconográfico se conforma de las imágenes constantes y de las aportaciones propias de cada sitio, como es el caso del Cristo de El Cajón y la Bok'yä completa (cabeza y cola) de El Tendido (figs. 11 y 13). De igual modo, en cada barranca se exalta un tema que puede establecer un diálogo en la región, por ejemplo, el sitio del El Cajón tiene un énfasis en los rituales de petición de lluvias, lo que alude a la época del año previa a estas. Mientras en El Boyé las numerosas representaciones de la "Serpiente de lluvia" insinúan que se reciben las bondades del agua. Así se señalan dos momentos diferentes del calendario ritual.

En este contexto la voluntad de crear significa y sacraliza el paisaje, que también responde a una manera de marcar el territorio y apropiarse de él. Así, la diseminación de los sitios no es fortuita ni tampoco 
simplista, ya que fue una expresión y estética propia de los otomíes para construir su espacio dentro del régimen español. Esto también expone la habilidad que tuvo este grupo para negociar con los frailes y con las autoridades españolas, pues las pinturas no están en lugares escondidos, incluso algunas se encuentran cerca de los antiguos asentamientos coloniales.

De esta manera, se expone la importancia que tuvo el uso de los diferentes recursos expresivos para el pueblo otomí, pues les permitió elegir una manera de ejercer su papel político, territorial, religioso e histórico en los tiempos cruciales del dominio español. Algunos rasgos de esta cosmovisión, como el sacrificio, aún perviven en los rituales de las comunidades otomíes del Mezquital.

Reconocimientos a la Dra. Marie-Areti Hers, a Rocío Gress y a Domingo España, miembros del proyecto. Asimismo, la traducción del resumen corrió a cargo de Carlos Misael Mancilla Hernández.

\section{NOTAS}

${ }^{1}$ Este trabajo fue realizado en el marco del proyecto "Arte y comunidades otomíes: metamorfosis de la memoria identitaria", segunda etapa del proyecto "La mazorca y el niño dios. El arte otomí: continuidad histórica y riqueza viva del Mezquital". Auspiciados por la Dirección General de Asuntos del Personal Académico y el Instituto de Investigaciones Estéticas de la Universidad Nacional Autónoma de México mediante el Programa de Apoyo a Proyectos de Investigación e Innovación Tecnológica (PAPIIT), clave IN402113.

${ }^{2}$ El proyecto de estudio del arte rupestre del valle del Mezquital ha contado con la participación de alumnos de distintos niveles académicos, quienes bajo la asesoría de Francisco Luna y la Dra. Marie-Areti Hers han desarrollado un proceso de investigación que ha puesto interés en distintas manifestaciones artísticas y culturales de los otomíes, como el arte rupestre, las capillas de linaje, el arte conventual y la ritualidad otomí contemporánea. En este proceso se han hecho registros fotográficos y de video, así como una amplia indagación de la historiografía de la región. Todo ello se ha traducido en diferentes trabajos académicos que buscan dar cuenta del complejo proceso del devenir histórico de este grupo.

${ }^{3}$ Para una discusión más amplia del contexto arqueológico e histórico particular del valle del Mezquital véase López Aguilar 1994, 2005; Fournier 2007.

\section{REFERENCIAS}

Albores, B., 2003. El culto mexica de los cerros de la cuenca de México: Apuntes para la discusión sobre graniceros. En Graniceros. Cosmovisión y meteorología indígena de México, J. Broda, Coord., pp. 51-90. México, D. F.: El Colegio Mexiquense A. C. Universidad Nacional Autónoma de México.

Alvarado Tezozómoc, F., 1992 [1949]. Crónica Mexicáyotl. México, D. F.: Instituto de Investigaciones Históricas, Universidad Nacional Autónoma de México.

Avilés, C., 2008. Pinturas rupestres de Tezoquipan. México, D. F.: Centro Estatal de Lenguas y Cultura Indígena, estado de Hidalgo.

Brambila, R., 2005. El centro de los otomíes. Arqueología Mexicana 73: 21-25, México, D. F.

Braniff, B., 1994. La frontera septentrional de Mesoamérica. En Historia Antigua de México, Vol. 1, L. Manzanilla \& L. López
Luján, Coords., pp. 113-143. México, D. F.: Instituto Nacional de Antropología e Historia, Universidad Nacional Autónoma de México, Porrúa.

Broda, J., 2001. La etnografía de la fiesta de la Santa Cruz: una perspectiva histórica. En Cosmovisión, ritual e identidad de los pueblos indigenas de México, J. Broda \& F. Baez-Jorge, Coords., pp.165-238. México, D. F.: Fondo de Cultura Económica.

Broda, J.; S. IwANISZEWSKI \& M. A. Miranda, 2001. La montaña en el paisaje ritual. México, D. F.: Instituto Nacional de Antropología e Historia.

CARrasco, P., 1979 [1950]. Los otomíes. Cultura e bistoria de los pueblos de habla otomiana. Toluca: Gobierno del Estado de México.

— 1996. Estructura político-territorial del Imperio Tenochca: la triple alianza de Tenochtitlan, Tetzcoco y Tlacopan. México, D. F.: El Colegio de México.

Castillo, A., 2004. Espacios sagrados. Una expresión de continuidad cultural. En Estudios de Cultura Otopame 4, pp. 155-169. México: Universidad Nacional Autónoma de México- Instituto de Investigaciones Antropológicas.

Fournier, P., 2007. Los hñähñü del Valle del Mezquital: Maguey, Pulque y Alfarería. México, D. F.: Instituto Nacional de Antropología e Historia.

Gelo del Toro, Y. \& F. López Aguilar, 1998. Hualtepec, Nonohualtepec y Cohualtepec. Lecturas de un cerro mítico. Arqueología 20: 65-78, México, D. F.

Gress, R., 2008. Voces de roca: el arte del Valle del Mezquital como fuente histórica. Tesis para optar al título de Licenciada en Historia, Facultad de Filosofía y Letras, Universidad Nacional Autónoma de México.

Hernández, N., 2013. Imágenes del cristianismo otomí. El arte rupestre del Cajón, estado de Hidalgo. Tesis para optar el título de Licenciada en Historia, Facultad de Filosofía y Letras, Universidad Nacional Autónoma de México.

Hers, M. A., 1989. Los toltecas en tierras chichimecas. México, D. F.: Universidad Nacional Autónoma de México, Instituto de Investigaciones Estéticas.

Hers, M. A.; A. Vite \& V. VAldovinos, en prensa. Arte rupestre en el Mezquital: identidad y dominio territorial en tiempos coloniales. En La vitalidad de las voces indigenas. Arte rupestre del contacto y en sociedades coloniales, F. Berrojalbiz, Ed. México, D. F.: Universidad Nacional Autónoma de México, Instituto de Investigaciones Estéticas.

HeYD, T., 2008. Introduction. En Aesthetics and Rock Art III Symposium, T. Heyd \& J. Clegg, Eds., pp. 1-3. London: BAR International Series 1818

Heyden, D., 1989. Aspectos mágico-religiosos de las cuevas. En Las máscaras de la cueva de Santa Ana Teloxloc, E. Vargas, Ed., pp. 91-96. México, D. F.: Universidad Nacional Autónoma de México.

Illera, C., 1994. Contenido simbólico de las pinturas rupestres del Valle del Mezquital. Tesis para optar al título de maestría en Arqueología. Arqueología, Escuela Nacional de Antropología e Historia.

KirchHoff, P., 1943. Mesoamérica. Sus límites geográficos, composición étnica y caracteres culturales. Acta América 1: 14-36, México, D. F.

LARA, J., 2008. Christian text for Aztec. Art and liturgy in Colonial Mexico. Indiana: University of Notre Dame Press.

Lastra, Y., 2006. Los otomies su lengua y su historia. México, D. F.: Universidad Nacional Autónoma de México-Instituto de Investigaciones Antropológicas.

López Aguilar, F., 1991. Estructura de las repúblicas de indios en los siglos xVI y xvII. En Nos queda la esperanza. El Valle del Mezquital, pp. 49-96. México, D. F.: Consejo Nacional para la Cultura y la Artes.

- 1992. Informe de la cuarta temporada de trabajo de campo 1991. Valle del Mezquital, Hidalgo. México, D. F.: Archivo Técnico del Instituto Nacional de Antropología e Historia.

- 1994. Historia prehispánica del valle del Mezquital. En Simposium sobre arqueología en el estado de Hidalgo. Trabajos recientes, 
1989, E. Fernández Dávila, Coord., pp. 113-123. México: D. F. Archivo de la Coordinación Nacional de Arqueología del INAH. 2005. Símbolos del tiempo: inestabilidad y bifurcaciones en los pueblos de indios de Valle del Mezquital. Pachuca: Consejo Estatal para la Cultura y las Artes de Hidalgo.

López Aguilar, F. \& M. Á. Trinidad, 1987. Proyecto valle del Mezquital. Informe de la primera temporada 1986-1987. Vol. 1 y 2. México, D. F.: Archivo Técnico del Instituto Nacional de Antropología e Historia.

López Aguilar, F. \& P. Fournier, 1989. Informe de la tercera temporada de trabajo de campo 1989. Proyecto Valle del Mezquital. México: Archivo Técnico del Instituto Nacional de Antropología e Historia.

2012. III. Peregrinaciones otomíes. Vínculos locales y regionales en el Valle del Mezquital. En Peregrinaciones ayer $y$ boy: arqueología y antropología de las religiones, P. Fournier, C. Mondragón \& W. Wiesheu, Eds., pp. 81-118. México, D. F.: El Colegio de México, Centro de estudios de Asia y África.

López Austin, A., 2001. El núcleo duro, la cosmovisión y la tradición mesoamericana. En Cosmovisión, ritual e identidad de los pueblos indígenas de México, J. Broda \& F. Baez-Jorge, Coords., pp. 47-66. México, D. F.: Fondo de Cultura Económica.

López Austin, A. \& López Luján, L., 2009. Monte Sagrado-Templo Mayor. México: Instituto Nacional de Antropología e HistoriaUniversida Nacional Autónoma de México-Instituto de Investigaciones Antropológicas.

Lorenzo C., 1992. Las pinturas rupestres: En el estado de Hidalgo, regiones $I V, V I, V I I$. México, D. F.: Instituto Hidalguense de Cultura.

Luna, F., En preparación. Ndä Kristo: rä Äjuä Nebbñu. Cristo: El Dios caminante. La historia otomí de la creación del mundo $y$ el hombre. Proyecto PAPIIT No IN402113.

Mastache, A., 2002. Ancient Tollan: Tula and the Toltec heartland. Niwot, Colorado: University Press of Colorado.

Ochatoma Paravicino, J., 1994. Cosmología y simbolismo en las pinturas rupestres del Valle del Mezquital. Tesis para optar al título de maestría en Arqueología. Arqueología, Escuela Nacional de Antropología e Historia.
PeÑA, D., 2014. Negrura de lluvia entre dioses: El arte rupestre de El Boyé. Tesis para optar el título de Licenciada en Historia, Facultad de Filosofía y Letras, Universidad Nacional Autónoma de México.

SÁnchez, S., 2004. Wemas y cangandhos: limpias con piedras en el Valle del Mezquital. En Historia y vida ceremonial en las comunidades mesoamericanas: los ritos agrícolas, J. Broda \& C. Good, Eds., pp. 298-303. México, D. F.: Universidad Nacional Autonóma de México-Instituto de investigaciones Históricas.

Sánchez VÁzQuez. A., 1992. Invitación a la estética. México, D. F. Grijalbo.

Soustelle, J., 1993 [1937]. La familia otomí-pame del México Central. México, D. F.: Centro de Estudios Mexicanos y Centroamericanos, Fondo de Cultura Económica.

Trejo, S., 2004. Dioses mitos y ritos de México Antiguo. México, D. F.: Miguel Ángel Porrúa.

VAldovinos, V., 2009. Boky'ä, la Serpiente de Lluvia en la tradición Nahñü del Valle del Mezquital. Tesis para optar el título de Licenciada en Historia, Facultad de Filosofía y Letras, Universidad Nacional Autónoma de México.

Viramontes, C., 2005. El lenguaje de los simbolos. El arte rupestre de las sociedades prehispánicas de Querétaro. Querétaro: Gobierno del estado de Querétaro.

Vite Hernández, A. 2012. El mecate de los tiempos. Continuidad en una comunidad hñähñu del Valle del Mezquital. Tesis para optar el título de Licenciado en Historia, Facultad de Filosofía y Letras, Universidad Nacional Autónoma de México.

WRIGHT, D., 1988. Conquistadores otomies en la guerra chicimeca: México: Gobierno del estado de Querétaro.

— 1994. La colonización de los estados de Guanajuato y Querétaro según las fuentes históricas. En Contribuciones a la arqueología y etnohistoria del Occidente de México, E. Williams, Ed., pp. 374-411. México, D. F.: El Colegio de Michoacán.

— 1995. El papel de los otomíes en las culturas del Altiplano Central: 5000 AC-1650 DC. En Otopames: Memoria del Primer Coloquio, Querétaro, F. Nava, Comp., pp. 323-336. México, D. F.: Universidad Nacional Autónoma de México, Instituto de Investigaciones Antropológicas.

2005. Lengua, cultura e historia de los otomíes. Arqueología Mexicana 73: 26-29, México, D. F. 